\title{
4 weeks of high-intensity interval training does not alter the exercise-induced growth hormone response in sedentary men
}

\author{
Hiroto Sasaki ${ }^{1}$, Takuma Morishima', Yuta Hasegawa' ${ }^{1}$, Ayaka Mori ${ }^{1}$, Toshiaki ljichi ${ }^{1}$, Toshiyuki Kurihara ${ }^{1,2}$ \\ and Kazushige Goto ${ }^{1,2^{*}}$
}

\begin{abstract}
Summary
This study determined the effects of high-intensity interval training on the exercise-induced growth hormone $(\mathrm{GH})$ responses, whole body and regional fat content. Twenty-four sedentary males were randomized to either a high-intensity interval training (HIT) group or a low-intensity continuous training (LT) group. The HIT group performed intermittent exercises at $85 \%$ of $\dot{V}_{2}$ max, whereas the LT group performed continuous exercise for 22 min at $45 \%$ of $\dot{\mathrm{V}}_{2 \text { max }}$. Before and after 4 weeks of training, hormonal and metabolic responses to acute exercise were determined. Acute exercise significantly increased GH concentrations in both groups $(p<0.05)$. However, the responses did not change after training period in either group. Furthermore, the training did not significantly affect intramyocellular or intrahepatic lipid content in either group. The present study indicates that 4 weeks of high-intensity interval training does not alter the exercise-induced GH responses, whole body fat mass or intramyocellular and intrahepatic lipid content in sedentary males.
\end{abstract}

Keywords: Endocrine response; Ectopic fat; Fat metabolism; Intensive exercise; Obesity

\section{Introduction}

Growth hormone (GH) has been shown to affect substrate oxidation pattern and body composition, because $\mathrm{GH}$ promotes lipolysis and fat oxidation (Gravholt et al. 1999). Administration of $\mathrm{GH}$ for 2 wk increases 24-h energy expenditure and fat oxidation (Hansen et al. 2005). GH secretion is also influenced by a variety of physiological conditions, including age, gender, nutrition status, body composition, and physical fitness level (Salvadori et al. 2010). Exercise, in particular, is a potent stimulus of GH secretion (Gilbert et al. 2008; Goto et al. 2007; Kanaley et al. 1997). The magnitude of exercise-induced GH secretion is dependent on the intensity (Pritzlaff et al. 1999) and duration of exercise (Wideman et al. 2006).

The accumulation of whole body and visceral fat mass strongly attenuates GH secretion (Makimura et al. 2008). Spontaneous (Eliakim et al. 2006; Kanaley et al. 1999) and

\footnotetext{
* Correspondence: kagoto@fc.ritsumei.ac.jp

${ }^{1}$ Graduate School of Sport and Health Science, Ritsumeikan University, Shiga, Japan

${ }^{2}$ Faculty of Sport and Health Sciences, Ritsumeikan University, 1-1-1, Nojihigashi, Kusatsu, Shiga 525-8577, Japan
}

exercise-induced (Rasmussen et al. 2008; Weltman et al. 2008) GH responses are impaired in obese people with marked abdominal fat accumulation compared with responses in people of normal weight. Furthermore, growing evidence suggests that accumulated fat in non-adipose tissue (ectopic fat) impairs GH secretion. For example, it was reported that the GH response to GHRH and arginine administration was attenuated by the accumulation of intramyocellular lipid (IMCL) (Misra et al. 2008). In addition, a previous study reported that intrahepatic lipid content (IHL) was negatively correlated with the peak GH concentration following GHRH and arginine administration (Bredella et al. 2009).

The increment of $\mathrm{GH}$ concentration during exercise is associated with the facilitation of lipolysis during the post-exercise period (Enevoldsen et al. 2007), and a positive correlation between peak GH concentration during exercise and fat oxidation during recovery was reported (Pritzlaff et al. 2000). Thus the exercise-induced GH secretion may have a favorable influence in terms of weight loss. Although GH secretion is generally attenuated in obese subjects, a great reduction in body weight caused 
by long-term caloric restriction increases $\mathrm{GH}$ secretion (Rasmussen et al. 2008). By contrast, a recent study demonstrated that moderate aerobic training for 4 weeks augmented the exercise-induced GH response with minimal or no weight loss in obese subjects (Salvadori et al. 2010), suggesting that aerobic training may be an effective tool for increasing GH secretion. Furthermore, considering that the exercise-induced $\mathrm{GH}$ response is dependent on exercise intensity, repetition of high-intensity interval training (HIT) may elicit greater improvement of the exercise-induced GH response compared with lower-intensity training.

Therefore, the purpose of the present study was to investigate the effects of HIT for 4 weeks on exercisedinduced GH secretion. We also determined changes in whole body fat mass, abdominal fat area, IMCL and IHL, which influence $\mathrm{GH}$ secretion. We hypothesized that HIT for 4 weeks would increase the magnitude of the exercise-induced $\mathrm{GH}$ response.

\section{Methods}

\section{Subjects}

Twenty-four healthy sedentary males participated in this study. Their height, weight and body mass index (BMI) were $172.5 \pm 1.4 \mathrm{~cm}, 71.2 \pm 2.0 \mathrm{~kg}$, and $23.9 \pm 0.5 \mathrm{~kg} / \mathrm{m}^{2}$, respectively (mean \pm standard error [SE]). All subjects were informed about the experiment procedure and purpose of this study. Their written informed consent was obtained subsequently. The study was approved by the Ethics Committee for Human Experiments at Ritsumeikan University, Japan.

\section{Study design and experimental protocol}

After completing baseline measurements, subjects were randomized to either the high-intensity interval training group (HIT group; $\mathrm{n}=12$ ) or low-intensity continuous training group (LT group; $\mathrm{n}=12$ ). None of the subjects were participating in any regular training program at the start of the experiment. There were no significant differences in baseline measurements regarding physical characteristics between the groups (Table 1). Subjects participated in the training program for 4 weeks (3 days/week, 12 sessions total). Although several types of HIT have been previously used (e.g., repeated bouts of 30s maximal pedaling; Burgomaster et al. 2006; Gibala and McGee 2008 we selected submaximal HIT model in term of practical application among normal people. Similar exercise protocol has been applied in a previous study for patients with type 2 diabetes (Little et al. 2011). Specifically, the HIT consisted of 10 sets of 1 min pedaling at 85\% of maximal oxygen uptake $\left(\dot{\mathrm{V}}_{2 \max }\right)$ with a $30 \mathrm{~s}$ rest between sets. The LT consisted of $22 \mathrm{~min}$ of continuous pedaling at $45 \%$ of $\dot{\mathrm{V}}_{2 \max }$, based on results of a preliminary
Table 1 Physical and metabolic parameters of subjects before and after training period

\begin{tabular}{lccc}
\hline & & Before training & After training \\
\hline \multirow{2}{*}{ Body weight $(\mathrm{kg})$} & HIT & $73.4 \pm 2.8$ & $73.7 \pm 2.9$ \\
& LT & $69.0 \pm 2.7$ & $69.4 \pm 2.8$ \\
\hline \multirow{2}{*}{$\mathrm{BMl}\left(\mathrm{kg} / \mathrm{m}^{2}\right)$} & HIT & $24.3 \pm 0.7$ & $24.4 \pm 0.7$ \\
\hline \multirow{2}{*}{ Percent fat (\%) } & LT & $23.4 \pm 0.8$ & $23.6 \pm 0.8$ \\
\hline \multirow{2}{*}{$\mathrm{V}_{2 \text { max }}(\mathrm{ml} / \mathrm{min})$} & HIT & $21.4 \pm 1.2$ & $20.9 \pm 1.3$ \\
& LT & $19.5 \pm 1.4$ & $19.9 \pm 1.4$ \\
\hline
\end{tabular}

Data are means $\pm \mathrm{SE}$. ${ }^{*} P<0.05$ versus before training.

study designed to ensure that energy expenditure during exercise was the same in both regimens. At the end of 2 weeks during training period, we measured $\dot{\mathrm{V}}_{2 \max }$ again to adjust workload in accordance with improvement of aerobic capacity (Data not shown). Heart rate (HR) was measured continuously using a wireless HR monitor (Polar RS400 ${ }^{\mathrm{ms}}$, Polar Electro Japan Co, Tokyo, Japan) in all training sessions. The rating of perceived exertion (RPE) was determined during the first and final training sessions (Borg 1973). Aerobic capacity and body composition were evaluated before and after training periods. We also determined hormonal and metabolic responses to acute exercise (30 min of continuous pedaling at $60 \%$ of $\dot{\mathrm{V}}_{2 \max }$ ) before and after training periods.

\section{Measurements before and after training periods Maximal oxygen uptake}

$\dot{\mathrm{V}} \mathrm{O}_{2 \text { max }}$ was assessed before and after training periods using a graded power test on a cycle ergometer (AEROBIKE 75XLIII, COMBI WELLNESS Co, Tokyo, Japan). The test began at $80 \mathrm{~W}$ and the load increased progressively in $30-\mathrm{W}$ increments every $2 \mathrm{~min}$ until exhaustion. The test was terminated when the subject failed to maintain the prescribed pedaling frequency of $80 \mathrm{rpm}$ or reached the plateau of $\dot{\mathrm{VO}}_{2}$. Respiratory gases were collected and analyzed using an automatic gas analyzer (AE300S, Minato Medical Science Co., Ltd, Tokyo, Japan). Data were averaged every $30 \mathrm{~s}$. HR was measured continuously using a wireless HR monitor (Polar RS400 ${ }^{\mathrm{mx}}$, Polar Electro Japan Co, Tokyo, Japan).

\section{Whole body fat mass and abdominal fat area}

Whole body and regional fat masses were determined before and after training periods. Whole body fat mass was evaluated using the bioimpedance method (In Body 720, BIOSPACE Co., Tokyo, Japan). Subcutaneous fat area of the abdomen (SFA) and visceral fat area (VFA) were measured with a 1.5-T magnetic resonance (MR) system (SignaHDxt 1.5 T GE Health Care UK Ltd, 
Buckinghamshire, England). During MR scans, the subject remained in the supine position. A series of transaxial MRI scans for the abdomen was acquired with a respiratory trigger (field of view $420 \times 420 \mathrm{~mm}$, slice thickness $10 \mathrm{~mm}$, no gap, $\mathrm{TE}=7.3 \mathrm{~ms}$, $\mathrm{TR}=$ one respiration). SFA and VFA were measured at the slice between L3 and L4 (L: Lumbar spine). All measurements were carried out by the same investigator using specially designed image analysis software (SliceOmatic 4.3, Tomovision Inc., Magog, Canada).

\section{IMCL and extramyocellular lipid content (EMCL)}

IMCL and EMCL were measured using a 1.5-T MR system (GE Healthcare Japan Co., Ltd, Tokyo, Japan) with an eight-channel body array coil. The subject's right thigh was positioned parallel to the main magnetic field. Multi-slice T1-weighted axial spin-echo images (TR/TE 600/7.8 ms, thickness $10 \mathrm{~mm}$, FOV $440 \times 440 \mathrm{~mm}$, matrix size $256 \times 256$ ) were initially acquired to guide the positioning of the volume of interest. Thereafter, single voxel proton magnetic resonance spectroscopy $\left({ }^{1} \mathrm{H}-\mathrm{MRS}\right)$ measurements were performed using the Point Resolved Spectroscopy (PRESS) sequence (TR/TE 2000/35 ms, $2 \times 2 \times 2 \mathrm{~cm}^{3}, 32$ acquisitions). The voxel was placed on the middle of the right vastus lateralis muscle at the midpoint between the greater trochanter and knee cleft. The voxel was placed carefully to avoid including visible interstitial tissue, subcutaneous fat or blood vessels. The spectrum was acquired without water suppression. Absolute concentrations of IMCL and EMCL were evaluated using LCModel software (version 6.3; S. Provencher, PhD, Oakville, Ontario, Canada) and the customized calculation reported by a previous study (Weis et al. 2009). The peak chemical shift of IMCL was adjusted to $1.3 \mathrm{ppm}$, and that of EMCL was adjusted to $1.5 \mathrm{ppm}$.

\section{IHL content}

IHL content was measured by a $1.5-\mathrm{T}$ MR system (SignaHDxt $1.5 \mathrm{~T}$ GE Health Care UK Ltd, Buckinghamshire, England) with an eight-channel body array coil. Transverse images of the liver were used to ensure accurate positioning of the voxel. A single voxel ${ }^{1} \mathrm{H}$-MRS was performed using the free-breathing PRESS sequence with a respiratory trigger $(\mathrm{TE}=26 \mathrm{~ms}, \mathrm{TR}=$ two respirations, $2 \times 2 \times 2 \mathrm{~cm}^{3}, 16$ acquisitions; 2048 data points over $2500 \mathrm{~Hz}$ spectral width). The voxel was placed within the posterior right lobe of the liver visually free from hepatic portal vein, gallbladder and fatty tissue. Post-processing of spectroscopic data was performed, and the combined liver lipid peaks (0.9, 1.3 and 2.0-2.2 ppm) were detected by a customized algorithm using LCModel software. Briefly, data were automatically scaled to an unsuppressed water peak (4.7 ppm), and the lipid content to the sum of water, and the lipid ratio (percent) were expressed. Abdominal transverse MRI images and spectra used to estimate IMCL, EMCL and IHL contents were obtained in the morning after an overnight fast.

\section{Assessment of hormonal and metabolic responses to acute exercise}

Before and after training periods, subjects arrived at the laboratory in the morning after fasting for $\geq 12 \mathrm{~h}$. The post-training visit was scheduled at least $48 \mathrm{~h}$ after the end of the training period to exclude acute effects of the final training session. After resting for $30 \mathrm{~min}$, a polyethylene catheter was inserted into an antecubital vein and a baseline blood sample was obtained. Subjects subsequently performed $30 \mathrm{~min}$ of a pedaling exercise at $60 \%$ of $\dot{\mathrm{VO}}_{2 \text { max }}$ with a cycle ergometer (exercise period, 0-30 min). After completing the exercise, subjects rested on a comfortable chair for $60 \mathrm{~min}$ (recovery period, 30-90 min). Venous blood samples were collected every $15 \mathrm{~min}$ during the exercise period and every $30 \mathrm{~min}$ during the recovery period to determine hormonal and metabolite responses to acute exercise (Figure 1).

Serum and plasma samples were prepared by $10 \mathrm{~min}$ of centrifugation and stored at $-80^{\circ} \mathrm{C}$ until analysis. From baseline samples, concentrations of blood glucose, serum cholesterol (HDL or LDL cholesterol), triglyceride (TG), free fatty acids (FFA), glycerol, GH, insulin, and cortisol were measured. Blood samples during exercise and the recovery period were used to determine concentrations of blood glucose, serum FFA, glycerol, GH, insulin, and cortisol.

Serum GH and cortisol concentrations were measured using radioimmunoassay (RIA) at a clinical laboratory (SRL, Inc., Tokyo, Japan). The intra-assay CVs after measurement were $2.6 \%$ for serum $\mathrm{GH}$ and $4.9 \%$ for serum cortisol. Serum insulin concentrations were also measured using a chemiluminescent enzyme immunoassay at the clinical laboratory. The intra-assay CV after measurement was $3.4 \%$ for serum insulin. Serum glycerol concentrations were determined in duplicate using a commercially available kit (Cayman Chemical Company, MI, USA). The intra-assay CV was $2.1 \%$ for serum glycerol. Serum FFA concentrations were measured using a commercially available enzymatic colorimetric kit (NEFA-HRII, Wako

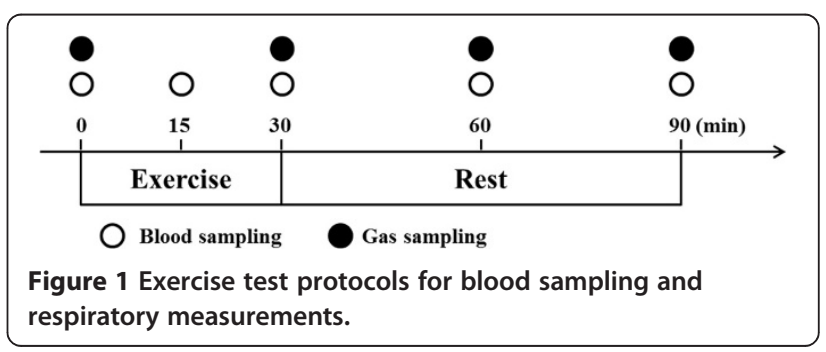


Pure Chemical Industries, Osaka, Japan). The intra-assay CV was $1.4 \%$ for serum FFA. Serum TG concentrations were measured using an enzymatic method at a clinical laboratory (SRL, Inc., Tokyo, Japan). The intra-assay CV was $2.6 \%$ for serum TG. Serum cholesterol concentrations were determined using ultraviolet absorption spectrophotometry at a clinical laboratory (SRL, Inc, Tokyo, Japan). The intra-assay CV was $1.4 \%$ for serum cholesterol.

Respiratory gases were collected to determine $\dot{\mathrm{VO}}_{2}$, carbon dioxide production $\left(\dot{\mathrm{V}}^{-\mathrm{CO}_{2}}\right)$ and ventilation volume during exercise and recovery periods. All measurements were performed in each 4-min period simultaneously with blood sampling, except for blood samples obtained at $15 \mathrm{~min}$ (Figure 1). The respiratory exchange ratio (RER) was calculated from $\dot{\mathrm{VO}}_{2}$ and $\dot{\mathrm{V}} \mathrm{CO}_{2}$ and used to estimate the relative contribution of fat (\% fat contribution) and carbohydrate oxidation (\% carbohydrate contribution) to total energy expenditure (Manetta et al. 2002). The percentage fat and carbohydrate contributions were calculated without measuring urinary nitrogen because of the negligible contribution of protein to substrate oxidation during exercise (Beidleman et al. 2002). Appropriate calibrations of $\mathrm{O}_{2}$ and $\mathrm{CO}_{2}$ sensors and the volume transducer were conducted prior to the start of exercise. HR was monitored continuously during exercise and recovery periods. The RPE was determined every $15 \mathrm{~min}$ during exercise.

\section{Physical activity and diet survey}

Subjects were advised to maintain their normal physical activity and diet throughout the experimental period. They wore an acceleration sensor (Actimarker, Panasonic Electric Works Co, Osaka, Japan) for 1 week, and daily physical activity was calculated from the obtained data. Daily energy intake was calculated using a brief-type self-administered diet history questionnaire (BDHQ) (Kobayashi et al. 2012). The BDHQ data were analyzed by an expert dietitian.

\section{Statistical analyses}

Data are expressed as means \pm SE for all variables. To compare body composition, physical fitness and baseline blood data between before and after training periods, a two-way (group [HIT, LT] $\times$ period [before and after training periods]) analysis of variance (ANOVA) with repeated measures was conducted. When ANOVA revealed a significant interaction or a main effect, post hoc tests were performed to assess where the difference occurred. Hormonal and metabolic responses to acute exercise were initially analyzed using a two-way (period [before and after training periods] $\times$ time $[0,15,30,60$, $90 \mathrm{~min}]$ ) ANOVA with repeated measures for each group and subsequent post hoc tests. Delta values of hormonal responses were compared between before and after training periods using a paired $t$-test. $P<0.05$ was considered to indicate a significant difference.

\section{Results}

\section{Physical characteristics and cardiorespiratory fitness}

Table 1 shows physical characteristics and $\dot{\mathrm{V}}_{2 \max }$ before and after training periods. There were no differences in body composition or $\dot{\mathrm{V}}_{2 \max }$ between the two groups before the training period. Body weight, BMI and percentage fat did not change significantly in either group between before and after training periods. $\dot{\mathrm{VO}}_{2 \max }$ increased significantly in both groups after the training period (HT; $8.3 \pm 2.6 \%$, LT; $4.7 \pm 1.3 \%$, compared with pre-training values, $p<0.05)$. However, there was no significant difference in the percentage change between groups.

\section{Fasting blood samples}

There were no differences in serum TG, HDL-cholesterol and LDL-cholesterol concentrations between HIT (TG; $72 \pm 8 \mathrm{mg} / \mathrm{dl}$, HDL-cholesterol; $51 \pm 2 \mathrm{mg} / \mathrm{dl}$, LDLcholesterol; $105 \pm 6 \mathrm{mg} / \mathrm{dl}$ ) and LT (TG; $80 \pm 10 \mathrm{mg} / \mathrm{dl}$, HDL-cholesterol; $53 \pm 4 \mathrm{mg} / \mathrm{dl}$, LDL-cholesterol; $88 \pm$ $6 \mathrm{mg} / \mathrm{dl}$ ) groups before the training period. These concentrations did not change significantly after the training period in either group.

\section{Abdominal fat area}

Table 2 shows abdominal fat area before and after training periods. Before the training period, VFA and SFA were not significantly different between groups. VFA and SFA did not change significantly after the training period in either group. Consequently, abdominal fat area, which was calculated by the sum of SFA and VFA, was not significantly different between before and after training periods in either group.

Table 2 Abdominal fat area before and after training period

\begin{tabular}{lccc}
\hline & & $\begin{array}{c}\text { Before } \\
\text { training }\end{array}$ & $\begin{array}{c}\text { After } \\
\text { training }\end{array}$ \\
\hline Subcutaneous fat area $\left(\mathrm{cm}^{2}\right)(\mathrm{SFA})$ & HIT & $153 \pm 16$ & $160 \pm 19$ \\
\hline Visceral fat area $\left(\mathrm{cm}^{2}\right)(\mathrm{VFA})$ & LT & $132 \pm 13$ & $132 \pm 12$ \\
\hline & HIT & $59 \pm 9$ & $57 \pm 4$ \\
Abdominal fat area $\left(\mathrm{cm}^{2}\right)$ & HIT & $211 \pm 17$ & $216 \pm 20$ \\
\hline
\end{tabular}

Values are means $\pm \mathrm{SE}$. Abdominal fat area indicates the sum of sucutaneous and visceral fat area. 


\section{IMCL and IHL content}

Table 3 shows IMCL, EMCL and IHL content before and after training periods. Before the training period, IMCL, EMCL and IHL contents were not significantly different between the groups. These values did not change significantly after the training period in either group.

\section{Hormonal responses to acute exercise}

Figure 2 shows the time course of changes in serum GH, insulin and cortisol concentrations during exercise and recovery periods. Before the training period, serum $\mathrm{GH}$ concentrations increased significantly during exercise in both groups $(p<0.05)$. Although a significant increase in serum GH concentration was found during exercise in both groups after the training period, the responses were not significantly different between before and after training periods in either group (Figure 2A). Serum insulin concentrations decreased significantly during exercise in both groups $(p<0.05)$. Although a significant decrease in serum insulin concentration was revealed after the training period, the responses were not significantly different between before and after training periods in either group (Figure 2B). Serum cortisol concentrations did not change significantly during exercise in either group, but decreased significantly during the recovery period in the LT group. Serum cortisol responses to exercise were similar between before and after training periods in both groups (Figure 2C). The area under the curve (AUC) of serum $\mathrm{GH}$, insulin and cortisol concentrations during exercise and recovery periods did not change significantly between before and after training periods in either group.

Figure 3 shows serum FFA and glycerol concentrations during exercise and recovery periods. Serum FFA concentrations decreased significantly during exercise in both groups $(p<0.05)$. However, serum FFA responses were similar between before and after training periods in both groups (Figure 3A). Before the training period, serum glycerol concentrations increased significantly during exercise in both groups $(p<0.05)$. Although serum glycerol concentrations increased significantly during exercise after training, the responses were not significantly different

Table 3 Intramyocellular lipid and intrahepatic lipid content before and after training period

\begin{tabular}{lccc}
\hline & & Before training & After training \\
\hline \multirow{2}{*}{ IMCL $(\mathrm{mmol} / \mathrm{kg})$} & HIT & $12.5 \pm 2.4$ & $14.2 \pm 2.5$ \\
& LT & $9.7 \pm 1.2$ & $10.4 \pm 1.7$ \\
\hline \multirow{2}{*}{ EMCL $(\mathrm{mmol} / \mathrm{kg})$} & HIT & $17.8 \pm 3.4$ & $20.5 \pm 3.2$ \\
& LT & $24.0 \pm 5.0$ & $22.3 \pm 3.8$ \\
\hline \multirow{2}{*}{ HL (arbitrary unit) } & HIT & $44.5 \pm 4.7$ & $46.6 \pm 4.3$ \\
& LT & $49.9 \pm 6.2$ & $46.8 \pm 7.2$ \\
\hline
\end{tabular}

Values are means \pm SE. IMCL; intramyocellular lipid content, EMCL; extracellular lipid content, IHL; intrahepatic lipid content. between before and after training periods in either group (Figure 3B). The AUCs of serum FFA and glycerol concentrations did not change significantly between before and after training periods in either group.

\section{Cardiorespiratory response to acute exercise}

Table 4 shows the cardiorespiratory and substrate oxidation responses during exercise and recovery periods. Before the training period, HR increased significantly during exercise in both groups $(p<0.05)$. After the training period, the peak HR during exercise tended to be lower than before training in the HIT group $(p=0.067)$.

$\dot{\mathrm{V}} \mathrm{O}_{2}$ and $\dot{\mathrm{V}} \mathrm{CO}_{2}$ during exercise and recovery periods were not significantly different between before and after training periods in either group. In addition, there were no significant differences in RER during exercise and recovery periods between before and after training periods in either group. Furthermore, the percentage carbohydrate or percentage fat contributions did not change significantly between before and after training periods in either group.

\section{Physical activity and diet survey}

Before the training period, estimated daily energy expenditure was not significantly different between groups (HIT group, $2331 \pm 83 \mathrm{kcal} /$ day vs. LT group, $2341 \pm 67 \mathrm{kcal} /$ day). These values did not change significantly after the training period in either group (HIT group, $2234 \pm 68 \mathrm{kcal} /$ day vs. LT group, $2290 \pm 81 \mathrm{kcal} /$ day).

Dietary energy intake estimated by BDHQ showed no significant difference between groups (HIT group, $2659 \pm 262 \mathrm{kcal} /$ day vs. LT group, $2261 \pm 258 \mathrm{kcal} /$ day) before the training period. No significant change was observed in dietary energy intake after the training period in either group (HIT group, $2375 \pm 209 \mathrm{kcal} /$ day vs. LT group, $2058 \pm 271 \mathrm{kcal} /$ day).

\section{Discussion}

To our knowledge, this is the first study to determine the effects of HIT on the exercise-induced GH response and ectopic fat accumulation. Our results indicate that the exercise-induced GH response was unaffected by 4 weeks of HIT. Additionally, there were no significant changes in IMCL or IHL between before or after high- or low-intensity training.

High-intensity anaerobic exercise (e.g., resistance exercise, sprint exercise) generally evokes a large increase in GH concentration after exercise (Gilbert et al. 2008; Collier et al. 2006; Stokes et al. 2002). However, previous studies have demonstrated that resistance training for 3 (Zajac et al. 2010) or 8 weeks (Kraemer et al. 1998) does not change the magnitude of resistance exercise-induced $\mathrm{GH}$ secretion. Furthermore, it was reported that 6 weeks of sprint training decreased the $\mathrm{GH}$ response to exercise 


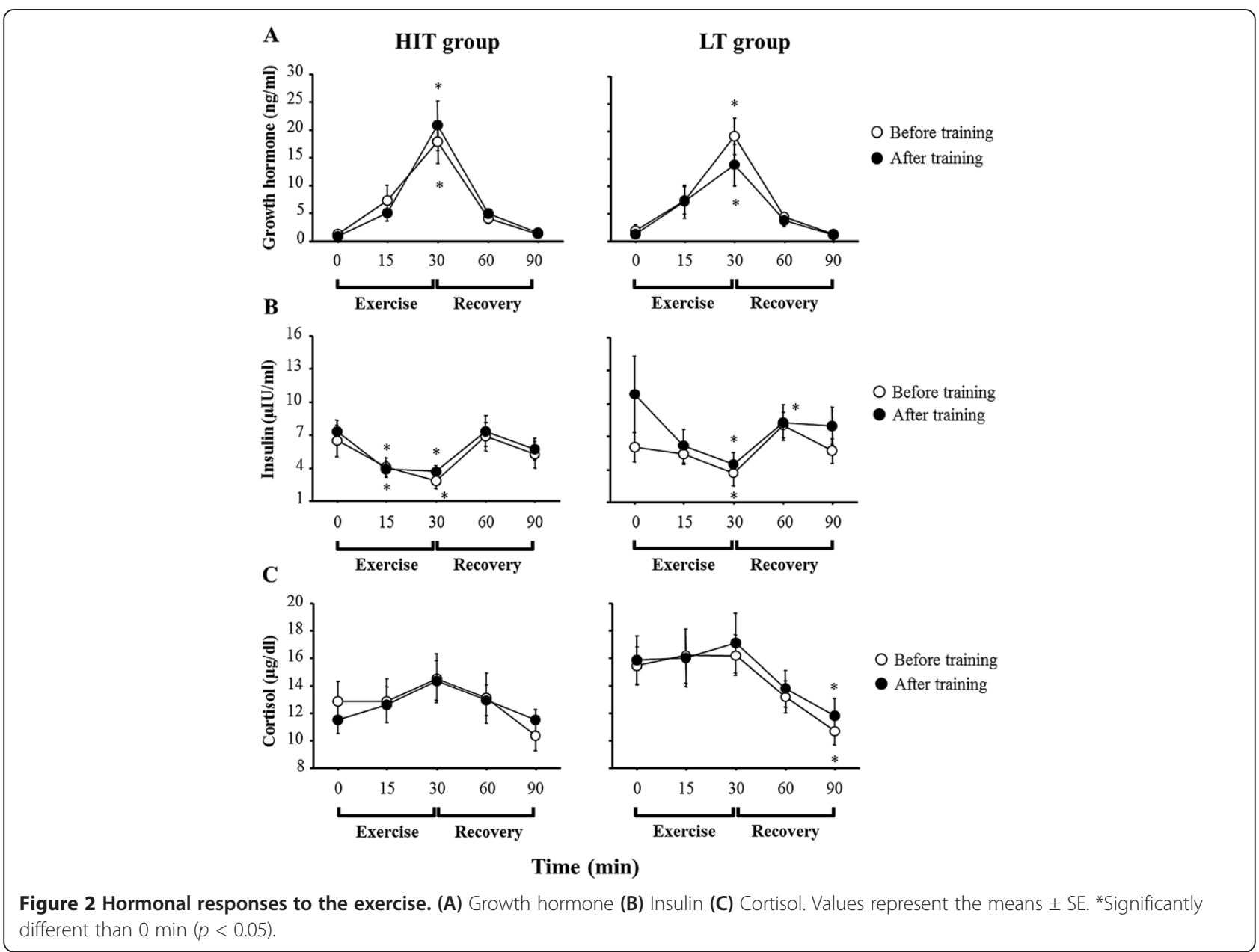

Figure 2 Hormonal responses to the exercise. (A) Growth hormone (B) Insulin (C) Cortisol. Values represent the means \pm SE. *Significantly different than 0 min $(p<0.05)$

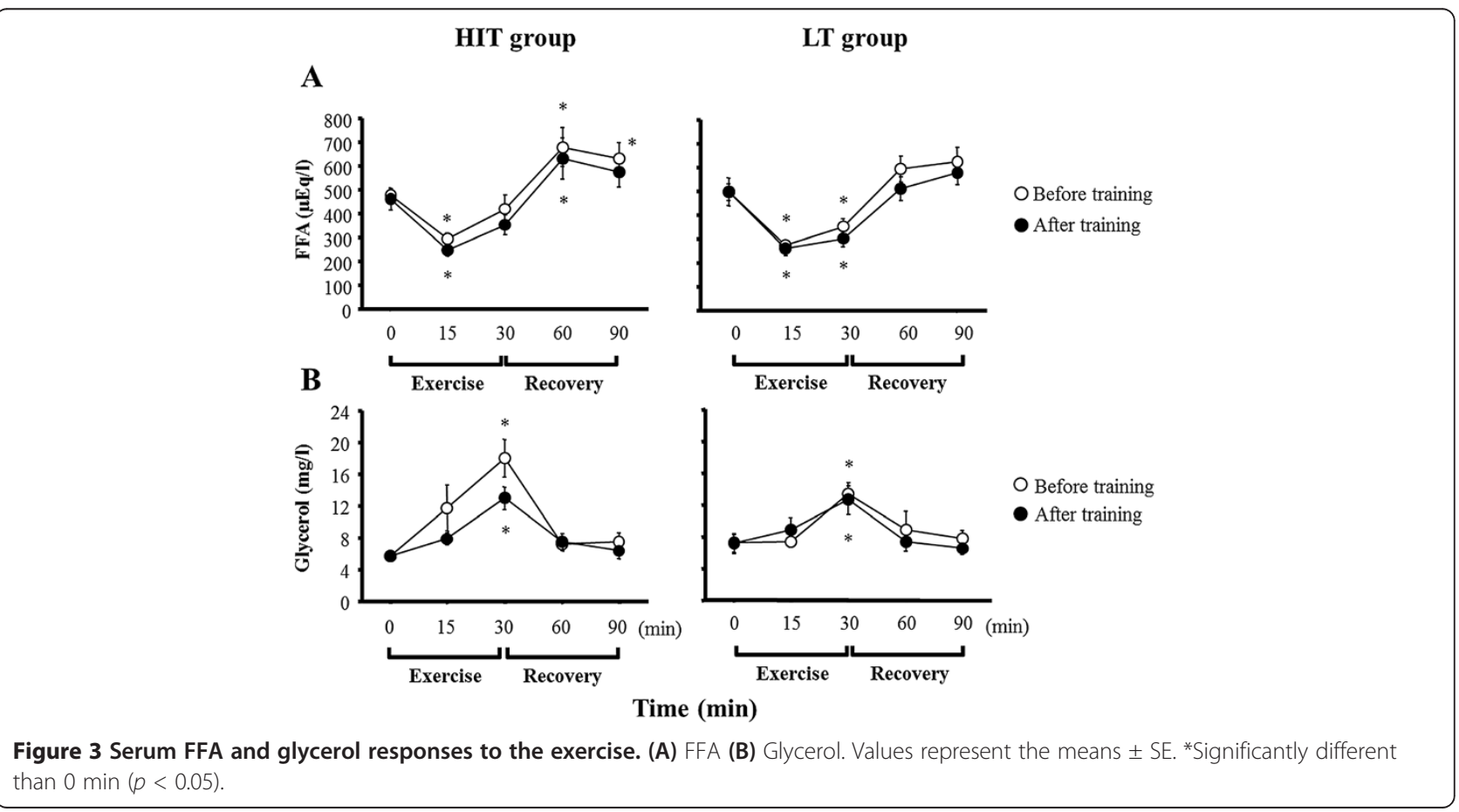


Table 4 Cardiorespiratory and substrate oxidation responses to $30 \mathrm{~min}$ exercise before and after training period

\begin{tabular}{|c|c|c|c|c|c|c|}
\hline Time & & & $0 \min$ & $30 \mathrm{~min}$ & $60 \mathrm{~min}$ & $90 \min$ \\
\hline \multirow{4}{*}{ Heart rate (bpm) } & \multirow{2}{*}{ HIT } & Before & $75 \pm 5$ & $163 \pm 5^{*}$ & $91 \pm 3^{*}$ & $82 \pm 3$ \\
\hline & & After & $73 \pm 3$ & $155 \pm 4^{*}$ & $97 \pm 4^{*}$ & $81 \pm 4^{*}$ \\
\hline & \multirow{2}{*}{ LT } & Before & $73 \pm 3$ & $167 \pm 4^{*}$ & $93 \pm 3^{*}$ & $86 \pm 3^{*}$ \\
\hline & & After & $70 \pm 3$ & $160 \pm 4^{*}$ & $99 \pm 3^{*}$ & $85 \pm 2^{*}$ \\
\hline \multirow{4}{*}{$\dot{\mathrm{V}} \mathrm{O}_{2}(\mathrm{ml} / \mathrm{min})$} & \multirow{2}{*}{ HIT } & Before & $260 \pm 14$ & $2041 \pm 101^{*}$ & $269 \pm 19$ & $269 \pm 12$ \\
\hline & & After & $253 \pm 15$ & $2157 \pm 107^{*}$ & $269 \pm 17$ & $268 \pm 20$ \\
\hline & \multirow{2}{*}{ LT } & Before & $258 \pm 11$ & $1953 \pm 99^{*}$ & $276 \pm 15$ & $261 \pm 15$ \\
\hline & & After & $243 \pm 17$ & $1953 \pm 120^{*}$ & $247 \pm 11$ & $251 \pm 14$ \\
\hline \multirow{4}{*}{$\dot{\mathrm{V}} \mathrm{CO}_{2}(\mathrm{ml} / \mathrm{min})$} & \multirow{2}{*}{ HIT } & Before & $211 \pm 13$ & $1924 \pm 102^{*}$ & $195 \pm 15$ & $210 \pm 12$ \\
\hline & & After & $200 \pm 13$ & $2056 \pm 97^{*}$ & $205 \pm 12$ & $208 \pm 15$ \\
\hline & \multirow{2}{*}{ LT } & Before & $211 \pm 9$ & $1892 \pm 101^{*}$ & $206 \pm 11$ & $203 \pm 11$ \\
\hline & & After & $207 \pm 18$ & $1919 \pm 116^{*}$ & $192 \pm 12$ & $198 \pm 12$ \\
\hline \multirow{4}{*}{ RER } & \multirow{2}{*}{ HIT } & Before & $0.81 \pm 0.02$ & $0.94 \pm 0.01^{*}$ & $0.73 \pm 0.02^{*}$ & $0.78 \pm 0.02$ \\
\hline & & After & $0.79 \pm 0.01$ & $0.96 \pm 0.01^{*}$ & $0.77 \pm 0.03$ & $0.78 \pm 0.02$ \\
\hline & \multirow{2}{*}{ LT } & Before & $0.83 \pm 0.01$ & $0.97 \pm 0.01^{*}$ & $0.75 \pm 0.01^{*}$ & $0.78 \pm 0.02^{*}$ \\
\hline & & After & $0.85 \pm 0.02$ & $0.99 \pm 0.01^{*}$ & $0.77 \pm 0.02^{*}$ & $0.79 \pm 0.02^{*}$ \\
\hline \multirow{4}{*}{ Carbohydrate contribution (\%) } & \multirow{2}{*}{ HIT } & Before & $35.4 \pm 7.3$ & $79 \pm 3.9^{*}$ & $11.9 \pm 4.0^{*}$ & $23.2 \pm 5.9$ \\
\hline & & After & $26.8 \pm 3.2$ & $84.6 \pm 2.8^{*}$ & $21.5 \pm 8.8$ & $25.5 \pm 6.7$ \\
\hline & \multirow{2}{*}{ LT } & Before & $39.7 \pm 4.7$ & $88.3 \pm 2.4^{*}$ & $12.9 \pm 3.5^{*}$ & $24.5 \pm 5.2^{*}$ \\
\hline & & After & $47.5 \pm 5.1$ & $91.9 \pm 2.0^{*}$ & $21.5 \pm 6.4^{*}$ & $27.6 \pm 4.9^{*}$ \\
\hline \multirow{4}{*}{ Fat contribution (\%) } & \multirow{2}{*}{ HIT } & Before & $64.6 \pm 7.3$ & $20.2 \pm 3.9^{*}$ & $88.1 \pm 3.9^{*}$ & $76.8 \pm 5.9$ \\
\hline & & After & $73.2 \pm 3.2$ & $15.4 \pm 2.8^{*}$ & $78.5 \pm 8.8$ & $74.5 \pm 6.7$ \\
\hline & \multirow{2}{*}{ LT } & Before & $60.4 \pm 4.7$ & $11.8 \pm 2.4^{*}$ & $87 \pm 3.5^{*}$ & $75.6 \pm 5.2^{*}$ \\
\hline & & After & $52.5 \pm 5.1$ & $8.2 \pm 2.0^{*}$ & $78.5 \pm 6.4^{*}$ & $72.4 \pm 4.9^{*}$ \\
\hline
\end{tabular}

Values are means \pm SE. ${ }^{*} ; P<0.05$ vs. 0 min. Carbohydrates and fat contributions indicate the relative utilization rate of energy resource to the total energy expenditure during $30 \mathrm{~min}$ exercise and $60 \mathrm{~min}$ recovery.

(Stokes et al. 2004). By contrast, a recent study (Salvadori et al. 2010) revealed that 4 weeks of moderateintensity aerobic training significantly increased the $\mathrm{GH}$ response to the same exercise, suggesting that exercise mode affects effects of training on the exercise-induced $\mathrm{GH}$ response.

In contrast to our hypothesis, the GH response to a single bout of exercise was not significantly different between before and after 4 weeks of low- or high-intensity training. There are several plausible reasons for the absence of changes in the GH response in the HIT group. First, the subjects in this study had relatively high GH responses to exercise at pre-training compared with those of obese subjects (Kanaley et al. 1999), which may influence the present results. Second, the accumulation of VFA, IMCL or IHL, which inhibit GH secretion (Makimura et al. 2008; Misra et al. 2008; Bredella et al. 2009), was not significantly different between before and after training periods in either group. Although aerobic training for longer duration substantially reduces VFA (Johnson et al. 2009; Heydari et al. 2012), the training program used in our study, which consisted of a relatively small training volume (14.5-22 $\mathrm{min} / \mathrm{session}$ ) and short duration (4 weeks), may be insufficient to alter exercise-induced $\mathrm{GH}$ secretion. In the present study, we have specifically focused on HIT, because growing evidences indicate that HIT promotes oxidative capacity in working muscles similar to traditional prolonged training (Burgomaster et al. 2008; Little et al. 2010; Hood et al. 2011). However, data from high-intensity continuous training group would be helpful to clarify impact of energy expenditure during exercise.

IMCL and IHL were measured using ${ }^{1} \mathrm{H}$-MRS before and after training periods, and no significant differences were found in either group. Aerobic training has previously shown to reduce IMCL in patients with type 2 diabetes (Tamura et al. 2005). By contrast, a previous study reported that 4 weeks of aerobic training without caloric restriction did not affect IMCL in obese individuals (Johnson et al. 2009), consistent with the present results. The inconsistent observation for IMCL in earlier studies can be explained by differences in experimental design, including whether the aerobic training was conducted in combination with 
caloric restriction. Information concerning the effect of exercise training on IHL content is limited, whereas IHL content has been shown to be reduced by caloric restriction alone and by exercise together with caloric restriction (Tamura et al. 2005; Shah et al. 2009; Vitola et al. 2009). Although several studies have shown that aerobic training without caloric restriction reduced IHL accumulation (Johnson et al. 2009; Keating et al. 2012; Bacchi et al. 2013), the effect of exercise training alone without caloric restriction on IHL content is not consistent among previous studies (Devries et al. 2008). Therefore, aerobic training combined with caloric restriction would be expected to reduce IMCL or IHL and subsequently improve GH secretion. Interestingly, in the present study, the exerciseinduced GH response did not correlate with either IMCL or IHL in all subjects $(n=24)$, but IHL content was inversely correlated with the exercise-induced GH response in obese subjects $(\mathrm{r}=-0.865, p<0.01, \mathrm{n}=8)$. Therefore, IHL accumulation seems to inhibit the exercise-induced GH response in a manner dependent on body composition.

Exercise-induced GH secretion augments fat metabolism during the post-exercise period (Enevoldsen et al. 2007; Wee et al. 2005). Thus, we hypothesized that the enhanced $\mathrm{GH}$ response following 4 weeks of HIT would increase exercise-induced lipolysis and fat oxidation. However, the hypothesis was not supported by our results because the time course of changes in serum glycerol and RER did not change significantly after 4 weeks of HIT. Moreover, insulin or cortisol responses to exercise, which also affect fat metabolism, were similar between before and after training periods in both groups.

The aim of this study was to determine the effect of HIT on the exercise-induced GH response in combination with detailed changes of whole body and regional fat content. However, our study had several limitations; we recruited healthy sedentary subjects with less fat accumulation and a greater exercise-induced GH response compared with obese people. Clearly, it was difficult to detect changes in endocrine regulations by training intervention. Therefore, further investigations using obese people are essential.

In conclusion, 4 weeks of HIT did not affect the magnitude of the exercise-induced $\mathrm{GH}$ response. In addition, the training intervention did not significantly change abdominal fat or IMCL or IHL content.

\section{Competing interest}

The authors declare that they have no competing interest.

\section{Authors' contributions}

HS participated in the critical conception and design, the acquisition of data, analysis and interpretation of data, drafting of the manuscript, and critical revision of the manuscript, and approved the final version. TM, YH, AM and TI helped to collect data. TK carried out ${ }^{1} \mathrm{H}$-MRS measurement before and after the intervention, and helped to draft of the manuscript and made revision of the manuscript. KG assisted mainly in the design, procedure and analysis of the experiment and in preparation of the manuscript. All authors read and approved the final manuscript.

\section{Acknowledgments}

We would like to thank all of the subjects who participated in this study. The authors are also grateful to Masako Moriya for helping conduct the diet survey. The present study was supported from Grant-in-Aid for Scientific Research from Japan Society for the Promotion of Science.

Received: 7 April 2014 Accepted: 24 June 2014

Published: 2 July 2014

\section{References}

Bacchi E, Negri C, Targher G, Faccioli N, Lanza M, Zoppini G, Zanolin E, Schena F, Bonora E, Moghetti P (2013) Both resistance training and aerobic training reduce hepatic fat content in type 2 diabetic subjects with nonalcoholic fatty liver disease (the RAED2 Randomized Trial). Hepatology 58:1287-1295

Beidleman BA, Rock PB, Muza SR, Fulco CS, Gibson LL, Kamimori GH, Cymerman A (2002) Substrate oxidation is altered in women during exercise upon acute altitude exposure. Med Sci Sports Exerc 34:430-437

Borg GA (1973) Perceived exertion: a note on "history" and methods. Med Sci Sports 5:90-93

Bredella MA, Torriani M, Thomas BJ, Ghomi RH, Brick DJ, Gerweck AV, Miller KK (2009) Peak growth hormone-releasing hormone-arginine-stimulated growth hormone is inversely associated with intramyocellular and intrahepatic lipid content in premenopausal women with obesity. J Clin Endocrinol Metab 94:3995-4002

Burgomaster KA, Heigenhauser GJ, Gibala MJ (2006) Effect of short-term sprint interval training on human skeletal muscle carbohydrate metabolism during exercise and time-trial performance. J Appl Physiol 100:2041-2047

Burgomaster KA, Howarth KR, Phillips SM, Rakobowchuk M, Macdonald MJ, McGee SL, Gibala MJ (2008) Similar metabolic adaptations during exercise after low volume sprint interval and traditional endurance training in humans. J Physiol 586:151-160

Collier SR, Collins E, Kanaley JA (2006) Oral arginine attenuates the growth hormone response to resistance exercise. J Appl Physiol 101:848-852

Devries MC, Samjoo IA, Hamadeh MJ, Tarnopolsky MA (2008) Effect of endurance exercise on hepatic lipid content, enzymes, and adiposity in men and women. Obesity (Silver Spring) 16:2281-2288

Eliakim A, Nemet D, Zaldivar F, McMurray RG, Culler FL, Galassetti P, Cooper DM (2006) Reduced exercise-associated response of the GH-IGF-I axis and catecholamines in obese children and adolescents. J Appl Physiol 100:1630-1637

Enevoldsen LH, Polak J, Simonsen L, Hammer T, Macdonald I, Crampes F, de Glisezinski I, Stich V, Bulow J (2007) Post-exercise abdominal, subcutaneous adipose tissue lipolysis in fasting subjects is inhibited by infusion of the somatostatin analogue octreotide. Clin Physiol Funct Imaging 27:320-326

Gibala MG, McGee SL (2008) Metabolic adaptations to short-term high-intensity interval training: a little pain for a lot of gain? Exerc Sport Sci Rev 36:58-63

Gilbert KL, Stokes KA, Hall GM, Thompson D (2008) Growth hormone responses to 3 different exercise bouts in 18- to 25- and 40- to 50-year-old men. Appl Physiol Nutr Metab 33:706-712

Goto K, Ishii N, Mizuno A, Takamatsu K (2007) Enhancement of fat metabolism by repeated bouts of moderate endurance exercise. J Appl Physiol 102:2158-2164

Gravholt CH, Schmitz O, Simonsen L, Bulow J, Christiansen JS, Moller N (1999) Effects of a physiological GH pulse on interstitial glycerol in abdominal and femoral adipose tissue. Am J Physiol 277:E848-E854

Hansen M, Morthorst R, Larsson B, Flyvbjerg A, Rasmussen MH, Orskov H, Astrup A, Kjaer M, Lange KH (2005) Effects of 2 wk of GH administration on 24-h indirect calorimetry in young, healthy, lean men. Am J Physiol Endocrinol Metab 289:E1030-E1038

Heydari M, Freund J, Boutcher SH (2012) The effect of high-intensity intermittent exercise on body composition of overweight young males. J Obes 2012:480467

Hood MS, Little JP, Tarnopolsky MA, Myslik F, Gibala MJ (2011) Low-volume interval training improves muscle oxidative capacity in sedentary adults. Med Sci Sports Exerc 43:1849-1856

Johnson NA, Sachinwalla T, Walton DW, Smith K, Armstrong A, Thompson MW, George J (2009) Aerobic exercise training reduces hepatic and visceral lipids in obese individuals without weight loss. Hepatology 50:1105-1112

Kanaley JA, Weltman JY, Veldhuis JD, Rogol AD, Hartman ML, Weltman A (1997) Human growth hormone response to repeated bouts of aerobic exercise. J Appl Physiol 83:1756-1761 
Kanaley JA, Weatherup-Dentes MM, Jaynes EB, Hartman ML (1999) Obesity attenuates the growth hormone response to exercise. J Clin Endocrinol Metab 84:3156-3161

Keating SE, Hackett DA, George J, Johnson NA (2012) Exercise and non-alcoholic fatty liver disease: a systematic review and meta-analysis. J Hepatol 57:157-166

Kobayashi S, Honda S, Murakami K, Sasaki S, Okubo H, Hirota N, Notsu A, Fukui M, Date C (2012) Both comprehensive and brief self-administered diet history questionnaires satisfactorily rank nutrient intakes in japanese adults. J Epidemiol 22:151-159

Kraemer WJ, Staron RS, Hagerman FC, Hikida RS, Fry AC, Gordon SE, Nindl BC, Gothshalk LA, Volek JS, Marx JO et al (1998) The effects of short-term resistance training on endocrine function in men and women. Eur J Appl Physiol Occup Physiol 78:69-76

Little JP, Safdar A, Wilkin GP, Tarnopolsky MA, Gibala MJ (2010) A practical model of low-volume high-intensity interval training induces mitochondrial biogenesis in human skeletal muscle: potential mechanisms. J Physiol 588:1011-1022

Little JP, Gillen JB, Percival ME, Safdar A, Tarnopolsky MA, Punthakee Z, Jung ME, Gibala MJ (2011) Low-volume high-intensity interval training reduces hyperglycemia and increases muscle mitochondrial capacity in patients with type 2 diabetes. J Appl Physiol 111:1554-1560

Makimura H, Stanley T, Mun D, You SM, Grinspoon S (2008) The effects of central adiposity on growth hormone $(\mathrm{GH})$ response to $\mathrm{GH}$-releasing hormone-arginine stimulation testing in men. J Clin Endocrinol Metab 93:4254-4260

Manetta J, Brun JF, Perez-Martin A, Callis A, Prefaut C, Mercier J (2002) Fuel oxidation during exercise in middle-aged men: Role of training and glucose disposal. Med Sci Sports Exerc 34:423-429

Misra M, Bredella MA, Tsai P, Mendes N, Miller KK, Klibanski A (2008) Lower growth hormone and higher cortisol are associated with greater visceral adiposity, intramyocellular lipids, and insulin resistance in overweight girls. Am J Physiol Endocrinol Metab 295:E385-E392

Pritzlaff CJ, Wideman L, Weltman JY, Abbott RD, Gutgesell ME, Hartman ML, Veldhuis JD, Weltman A (1999) Impact of acute exercise intensity on pulsatile growth hormone release in men. J Appl Physiol 87:498-504

Pritzlaff CJ, Wideman L, Blumer J, Jensen M, Abbott RD, Gaesser GA, Veldhuis JD, Weltman A (2000) Catecholamine release, growth hormone secretion, and energy expenditure during exercise vs. recovery in men. J Appl Physiol 89:937-946

Rasmussen MH, Wildschiodtz G, Juul A, Hilsted J (2008) Polysomnographic sleep, growth hormone insulin-like growth factor-l axis, leptin, and weight loss. Obesity (Silver Spring) 16:1516-1521

Salvadori A, Fanari P, Marzullo P, Codecasa F, Tovaglieri I, Cornacchia M, Walker G, Brunani A, Longhini E (2010) Dynamics of GH secretion during incremental exercise in obesity, before and after a short period of training at different work-loads. Clin Endocrinol (Oxf) 73:491-496

Shah K, Stufflebam A, Hilton TN, Sinacore DR, Klein S, Villareal DT (2009) Diet and exercise interventions reduce intrahepatic fat content and improve insulin sensitivity in obese older adults. Obesity (Silver Spring) 17:2162-2168

Stokes KA, Nevill ME, Hall GM, Lakomy HK (2002) Growth hormone responses to repeated maximal cycle ergometer exercise at different pedaling rates. J Appl Physiol 92:602-608

Stokes KA, Nevill ME, Cherry PW, Lakomy HK, Hall GM (2004) Effect of 6 weeks of sprint training on growth hormone responses to sprinting. Eur J Appl Physiol 92:26-32

Tamura Y, Tanaka Y, Sato F, Choi JB, Watada H, Niwa M, Kinoshita J, Ooka A, Kumashiro N, Igarashi Y, Kyogoku S, Maehara T, Kawasumi M, Hirose T, Kawamori R (2005) Effects of diet and exercise on muscle and liver intracellular lipid contents and insulin sensitivity in type 2 diabetic patients. J Clin Endocrinol Metab 90:3191-3196

Vitola BE, Deivanayagam S, Stein RI, Mohammed BS, Magkos F, Kirk EP, Klein S (2009) Weight loss reduces liver fat and improves hepatic and skeletal muscle insulin sensitivity in obese adolescents. Obesity (Silver Spring) 17:1744-1748

Wee J, Charlton C, Simpson H, Jackson NC, Shojaee-Moradie F, Stolinski M, Pentecost C, Umpleby AM (2005) GH secretion in acute exercise may result in post-exercise lipolysis. Growth Horm IGF Res 15:397-404

Weis J, Johansson L, Ortiz-Nieto F, Ahlstrom H (2009) Assessment of lipids in skeletal muscle by LCModel and AMARES. J Magn Reson Imaging 30:1124-1129

Weltman A, Weltman JY, Watson Winfield DD, Frick K, Patrie J, Kok P, Keenan DM, Gaesser GA, Veldhuis JD (2008) Effects of continuous versus intermittent exercise, obesity, and gender on growth hormone secretion. J Clin Endocrinol Metab 93:4711-4720
Wideman L, Consitt L, Patrie J, Swearingin B, Bloomer R, Davis P, Weltman A (2006) The impact of sex and exercise duration on growth hormone secretion. J Appl Physiol 101:1641-1647

Zajac A, Poprzecki S, Zebrowska A, Chalimoniuk M, Langfort J (2010) Arginine and ornithine supplementation increases growth hormone and insulin-like growth factor-1 serum levels after heavy-resistance exercise in strength-trained athletes. J Strength Cond Res 24:1082-1090

doi:10.1186/2193-1801-3-336

Cite this article as: Sasaki et al:: 4 weeks of high-intensity interval training does not alter the exercise-induced growth hormone response in sedentary men. SpringerPlus 2014 3:336.

\section{Submit your manuscript to a SpringerOpen ${ }^{\odot}$ journal and benefit from:}

- Convenient online submission

- Rigorous peer review

- Immediate publication on acceptance

- Open access: articles freely available online

- High visibility within the field

- Retaining the copyright to your article

Submit your next manuscript at $>$ springeropen.com 